\title{
$5 \mathrm{G}$ 移动通信网络的关键技术分析
}

\author{
李祥中 \\ 江苏省邮电规划设计院有限责任公司，江苏南京 210019
}

[摘要] 随着科技的进步, 越来越多的网络技术涌现, $5 \mathrm{G}$ 移动通信网络技术作为新兴发展项目, 得到了广泛的应用, 成为
了电信事业中的关键业务。在 $4 \mathrm{G}$ 技术普及的形势下, 为了满足日益增长的移动通信设备的需求, 大力发展 $5 \mathrm{G}$ 移动通信
网络, 本文对 $5 \mathrm{G}$ 移动通信网络技术的优势以及其关键技术的应用进行了探讨。
[关键词] 移动通信网络; $5 \mathrm{G}$; 关键技术; 应用

近年来, 社会经济发展迅速, $4 \mathrm{G}$ 网络得到了全面的普及, 当前移动通信的主要目标转变为了高水平的移动网络。 面对海量的移动数据, 以往的 $2 \mathrm{G} 、 3 \mathrm{G} 、 4 \mathrm{G}$ 通信仍无法满足其基本的需求, $5 \mathrm{G}$ 移动通信网络应运而生, 对 $5 \mathrm{G}$ 移动通信 网络中的关键技术进行科学的规划和应用, 提高 $5 \mathrm{G}$ 网络的稳定性, 创造良好的移动数据运行环境。

\section{$15 \mathrm{G}$ 移动通信网络技术分析}

在现代化移动通信网络全面普及的形势下, $5 \mathrm{G}$ 移动通信网络技术是当前社会大力发展的网络项目, 将成为未来移 动系统的主流, 电信运营商正在积极的开展相关研究, 对未来网络技术的应用进行详细的规划, 为 $5 \mathrm{G}$ 移动通信网络的 发展创造良好的环境。据相关专业人士预测, 在 2020 年将会实现 $5 \mathrm{G}$ 移动通信网络技术的正式运营, 与以往的 $4 \mathrm{G}$ 移动 网络相比, 有着更快的网络传输速度和网络资源服务范围, 信号的稳定性增强, 有着明显的优势 ${ }^{[1]}$ 。5G 移动通信网络 的运行, 将会极大的改善数据网络的运行条件, 因此, 各大电信运营商应紧跟时代潮流, 大力发展 5G 移动通信网络, 探索网络中的关键技术, 为 $5 \mathrm{G}$ 移动通信网络的运行提供良好的条件。

\section{$25 \mathrm{G}$ 移动通信网络技术特征}

$5 \mathrm{G}$ 移动通信网络技术特征具体表现在以下三个方面: 第一, $5 \mathrm{G}$ 移动通信网络技术优化了用户体验, 提高了数据资 源的传输效率, 增加了许多移动业务, 确保了用户在使用过程中信息服务的流畅性和稳定性。第二, $5 \mathrm{G}$ 移动通信网络 打破了以往点对点的传输方式, 转变为了多点、多用户的运行方式, 大大提高了网络运行的效率。第三, $5 \mathrm{G}$ 移动通信 网络打破了传统的 “争取覆盖” 的运行方式, 在室内信号全覆盖时充分发挥了高频段资源的作用, 增强了信号的穿透力, 提高了无线信号的优质性 ${ }^{[2]}$ 。

\section{$35 \mathrm{G}$ 移动通信网络技术应用}

\section{$3.1 \mathrm{SDN} / \mathrm{NFV}$ 技术}

可扩展技术是 $5 \mathrm{G}$ 移动通信网络中最重要技术之一。近年来, 云技术服务、三网融合等产业迅速发展, 为 $5 \mathrm{G}$ 移动 通信网络的发展提供了技术规划, 包括网络安全性、可开展等方面。SDN 指的是软件定义网络, NFV 指的是网络功能虚 拟化, 作为 $5 \mathrm{G}$ 移动通信网络中的新型构架, SDN/NFV 技术很好的控制了数据的分离, 实现了网络功能的虚拟化和软件化, 为 $5 \mathrm{G}$ 移动通信网络的发展奠定了良好的基础。 $\mathrm{SDN} / \mathrm{NFV}$ 技术通过网络构建了网络通信的三个层面, 即基础层、控制层 和应用层, 结合开放的 API, 将以往手动配置的方式转变为程序上的调用, 大大简化了 $5 \mathrm{G}$ 移动通信网络的管理, 提高 了网络管理的效率 ${ }^{[3]}$ 。转发分离功能是 $5 \mathrm{G}$ 移动通信网络必须具备的功能, 能够对整个网络通信系统进行优化, 实现了 $5 \mathrm{G}$ 移动通信网络运行的有效控制。SDN 与 NFV 技术的融合, 构建了虚拟网络的框架, 能够满足各种业务的要求。

\section{2 自组织网络技术}

从技术原理方面来说, 自组织网络技术指的是将专业化的自组织能力适当的引入到网络技术当中, 包括自我配置、 自我优化等, 将 $5 \mathrm{G}$ 移动网络技术与以往的通信技术进行区分, 降低人工干预程度, 实现人力资源和物理资源等效果的 最大化和最优化。当前自组织网络有着广阔的发展前景。从专业化方面来说, $5 \mathrm{G}$ 移动通信网络是一种异构网络, 随着 业务的不断变化, 工作人员应及时掌握网络动态, 实施相应的调整, 不断进行目标的优化选择, 例如可以通过双连接 等形式。

\section{3 全双工技术}

全双工技术指的是在相同频率的状态下, 进行的一种双向通信技术 ${ }^{[4]}$ 。现阶段, 现代化移动通信网络的接收站以 及网络终端都安装了干扰发射器, 能够按照一定的模式运行, 但是当前掌握的技术无法在相同频率下实现双向化通信。 就理论和技术方面来说, 全双工技术能够提高数据传输和频谱使用的灵活性, 从某种程度上说能够提高通信频率的工 作效率。在实际工作中, 现有的信号处理技术不完善, 很多设备性能有待优化, 严重阻碍了全双工技术的发展。随着 对全双工技术研究的深入, 未来必定会成为 $5 \mathrm{G}$ 移动通信的关键内容, 实现全双工技术的全面普及。 


\section{4 超密集异构网络技术}

$5 \mathrm{G}$ 移动通信网络关键技术仍处于初步的探索阶段, 很多关键内容有待进一步开发和研究。在新时代的大背景下, $5 \mathrm{G}$ 移动通信网络会呈现出网络多元化的发展趋势, 逐渐实现宽带的智能化。未来 $5 \mathrm{G}$ 移动通信网络数据将会大大提升其 数据流量, 这一技术便为超密集异构网络技术。近年来, 对超密集异构网络技术的研究越来越深入, 随着该技术的逐 渐应用, 在未来几年内, 无线网络无线节点将会大量增加, 从宏站来说, 其覆盖区域内的站点之间的距离会不断减小, 最终控制在 $10 \mathrm{~m}$ 以内, 同时在区域内 $1 \mathrm{~km}^{2}$ 会涵盖 25000 个用户服务 ${ }^{[5]}$ 。随着新网络技术的全面普及, 用户的规模和活 跃度将会大大提高, 用户会获得高质量的网络服务和极速的上网体验。用户与服务节点之间将会形成一种相互对应的 关系, 大大提升了上午速度。除此之外, 随着网络技术的发展, 人们对生活习惯逐渐发生了改变, 对无线网络的需求 量也越来越大, 现在很多学校、医院、商场等公共场所都覆盖了无线网, 为人们的日常工作、学习与娱乐提供了方便。 因此当前无线网络正处于快速发展的阶段, 需要国家的大力支撑, 为无线网络的发展提供资金支持和政策支持, 促进 无线通信网络的可持续发展, 服务于广大人民群众。

\section{$3.5 \mathrm{MIMO}$ 技术}

与传统形式的网络技术相比, MIMO 技术在空间分辨率上有着明显的优势, 能够为用户提供更为清晰的画面。当前 MIMO 技术发展迅速, 应准确把握其维度, 充分挖掘其发展潜力, 让不同用户能够在同一时间进行高效的自由通信, 保 证实际基站的密度, 不断提高频谱效率 ${ }^{[6]}$ 。同时, MIMO 技术能够将波束集中在一起, 然后将其分散到狭窄区域, 避免 产生干扰, 进而提升功效。但是当前 MIMO 技术的发展还存在很多不足, 例如, 受到传输方案的限制, 多数的应用系统 都是属于 TDD 系统, 在其发展过程中, 基本的设备都是单天线, 因此导致了实际的数量要少于基站天线数量, 随着用 户数量的增加, 导频数量也随之增多。

\section{4 结束语}

综上所述, 随着时代的发展, $4 \mathrm{G}$ 网络的全面普及, 移动通信网络的需求量越来越大, 人们对于移动通信网络的质量、 安全以及快速性的要求越来越高, $5 \mathrm{G}$ 网络时代即将到来。对 $5 \mathrm{G}$ 移动通信网络的关键技术进行分析和研究, 有利于推动 $5 \mathrm{G}$ 网络的发展, 移动通信网络将会迈向一个新时代。

\section{[参考文献]}

[1] 李佳, 刘胜达, 王玮。 5G 移动通信网络关键技术论述 [J]。通讯世界, 2016(07)：96-97.

[2] 吴强。 $5 \mathrm{G}$ 移动通信发展趋势与若干关键技术分析 [J]。教育教学论坛, 2016 (22) : 82-83.

[3] 唐忠杰。关于 $5 \mathrm{G}$ 移动通信发展趋势分析及若干关键技术探讨 [J]。中国新通信 , 2016, 18 (20) : 6-7.

[4] 杨松朔，何海浪。基于 SDN 技术分析 $5 \mathrm{G}$ 移动通信网络架构 $[\mathrm{J}]$. 科技风, 2017(06) : 111.

[5] 钱承远. $5 \mathrm{G}$ 移动通信关键技术的分析及其未来发展前景 $[\mathrm{J}]$ 。通讯世界, 2017 (14) : 125-126.

[6] 席玮。探究 $5 \mathrm{G}$ 移动通信技术下传输未来发展趋势 [J]。通讯世界, 2017 (23) : 52-54. 